\title{
Transitioning to Independent Practice: A Successful Fourth-Year Radiology Resident Curriculum
}

\author{
Darel E. Heitkamp, MD, Jason M. Ford, MD, Colleen M. Madden, MD, Kevin L. Smith, MD, \\ Matthew J. Nartker, MD, John M. Ponting, MD, Scott D. Steenburg, Vasantha D. Aaron, MD, \\ Aaron P. Kamer, MD
}

\section{THE PROBLEM}

In 2007, the ABR announced changes to the structure and timing of the diagnostic radiology board examinations that would effectively consolidate testing into two examinations, a qualifying examination at the end of the third year of residency and a certifying examination 15 months after graduation. At the same time, the Radiology Residency Review Committee announced that the new board examination structure would enable a functional partitioning of radiology residency into a 3 -year "core" period before the qualifying examination, followed by the fourth year of residency after it. The core years, it was reasoned, would be a time to focus on acquiring the fundamental concepts and skills of radiology, and the fourth year would be an opportunity for trainees to gain additional experience in subspecialty areas of interest that would allow them to bring valueadded skills to patients and clinical care providers once in practice.

In the decade since these joint announcements, programs have worked hard to define their new fourth-year resident curricula. The redesigned fourth year provides opportunities for residents to focus on improving clinical skills before independent practice in ways that were not possible in the days of the oral boards [1]. New clinical experiences can be fashioned to expose our most seasoned residents to high volumes of cases or provide them with specific image-guided interventions with which they may need more experience. Additionally, today's fourth-year residents can assume the role of "acting fellow" or even "junior faculty" on services, troubleshooting problems, providing protocols to technologists, helping clinicians formulate patient care plans, providing support for multidisciplinary conferences, and helping teach junior residents and medical students.

In practice, however, the process of building effective fourth-year curricula for many programs has been slow to evolve. Most residency programs have finite educational resources and cannot easily accommodate many additional rotations for their fourth-year residents without inadvertently diluting the educational experiences for their existing core residents and fellows [2]. For example, programs tend to have fixed numbers of available radiology faculty, image-guided procedures, interventional radiology suites, PACS workstations, and cross-sectional imaging studies. Launching a new fourth-year resident curriculum effectively introduces a third category of learner that competes for the same limited pool of resources in the daily workflow. Educators at our institution felt that this new residency structure dilemma was an actionable problem to solve: How do we provide fourthyear residents with a rigorous curriculum enabling the stepwise transition to independent practice while being careful to preserve the educational experience of other learners in the department?

\section{WHAT WAS DONE}

\section{A New Fourth-Year Transitional Curriculum}

In July 2015, the Education Division of the Indiana University Department of Radiology implemented a new curriculum for fourthyear residents intended to more fully embrace the Radiology Residency Review Committee's residency restructuring vision. The goal of the curriculum was to provide a highyield clinical learning experience focused on transitioning fourth-year residents to independent practice.

This is the author's manuscript of the article published in final edited form as: 
This article is intended to highlight the basic elements of this curriculum and review the initial outcomes data as measured by a survey of the first class to complete it.

\section{Elements of the Fourth-Year Curriculum}

High-Volume Electives. Perhaps the most crucial elements of the new fourth-year curriculum are the electives that provide the kind of highvolume, fast-paced workflow that best mimics private practice. These rotations allow senior residents to function semi-independently alongside our radiology faculty to better develop their skills of procedure efficiency, report generation speed, multitasking, and collaboration with clinicians of other specialties. The mainstay of our high-volume electives is resident participation at the four busy private suburban hospitals within our health care system, where they can function as junior faculty without competing for imaging studies and procedures with other trainees. Rotating at these hospitals provides a general radiology experience that best mimics private practice, with high volumes of all imaging modalities, including cross-sectional CT and MRI, image-guided interventions, and basic fluoroscopic procedures such as gastrointestinal fluoroscopy, lumbar punctures, myelograms, and arthrograms.

In addition to the general radiology electives, we offer high-volume experiences in focused areas, such as after-hours emergency radiology, after-hours emergency neuroradiology, daytime general neuroradiology, private practice breast imaging, private practice interventional radiology, body MRI, body procedures, and pediatric radiology. On these rotations, the fourth-year resident is either the only trainee on service or functions as the "acting fellow," and is free to dictate cases, work up patients, and make many decisions semiautonomously. The private practice breast imaging rotation is a special experience that truly enables the transition to independent practice by allowing fourth-year residents to make decisions and workup patients semiindependently.

Clinical Immersion Electives. The second important element to the fourth-year curriculum is the clinical immersion experience. Residents can elect to spend time embedded with clinical care providers who practice in their intended fellowship areas so that they might better understand principles of patient management. The chance to spend meaningful time interacting with patients again after 3 years of dedicated radiology training helps residents identify areas where they might bring value to patient care in their radiology practice. It's also a tremendous opportunity to ask subspecialty clinicians how they think radiologists might best add value to patient care and what specific items they look for in the radiology report. The residents must be proactive in arranging the elective: They must contact and obtain approval from the clinical faculty, they must create a clear list of goals and objectives for the rotation, and they must write a list of questions for the clinical faculty members as they pertain to patient management and opportunities for added radiology value.

Clinical immersion electives have been completed in several subspecialty areas to date. One resident participated in an elective focusing on breast cancer care, spending 2 weeks with a breast medical oncologist, 1 week with a breast surgeon, and 1 week with a breast pathologist. Another resident created an elective focusing on the clinical management of arthritis, spending 2 weeks with a rheumatologist and 2 weeks with an orthopedic surgeon. Residents have also created electives in interventional radiology, spending time with hepatologists and liver transplant surgeons to better understand liver tumor management, or spending time with vascular surgeons to better understand vascular surgery technique.

Special Skills Electives. The third component of the fourth-year curriculum is the special skills elective. These are procedure electives completed with nonphysician health care providers that are designed to provide residents with added experience in specific procedures of interest to them. The three special skills electives that are routinely scheduled by fourth-year residents are placement of peripherally inserted central catheters with the PICC nurse team, hands-on ultrasound scanning with the ultrasound technologists, and adult port placement with the radiology physician assistant. The handson ultrasound scanning rotation is often tailored to include specific ultrasound examinations that correspond to the resident's fellowship area of interest, such as transplant, obstetric, pediatric, or abdominal ultrasounds. Fourth-year residents are required to prearrange these electives with the health care providers who perform the procedures.

Multidisciplinary Conferences. The final element of the fourth-year curriculum is the required management of a department multidisciplinary conference. Each rising fourth-year resident is assigned to the weekly departmental multidisciplinary conference that best matches his or her ranked preference as determined by 


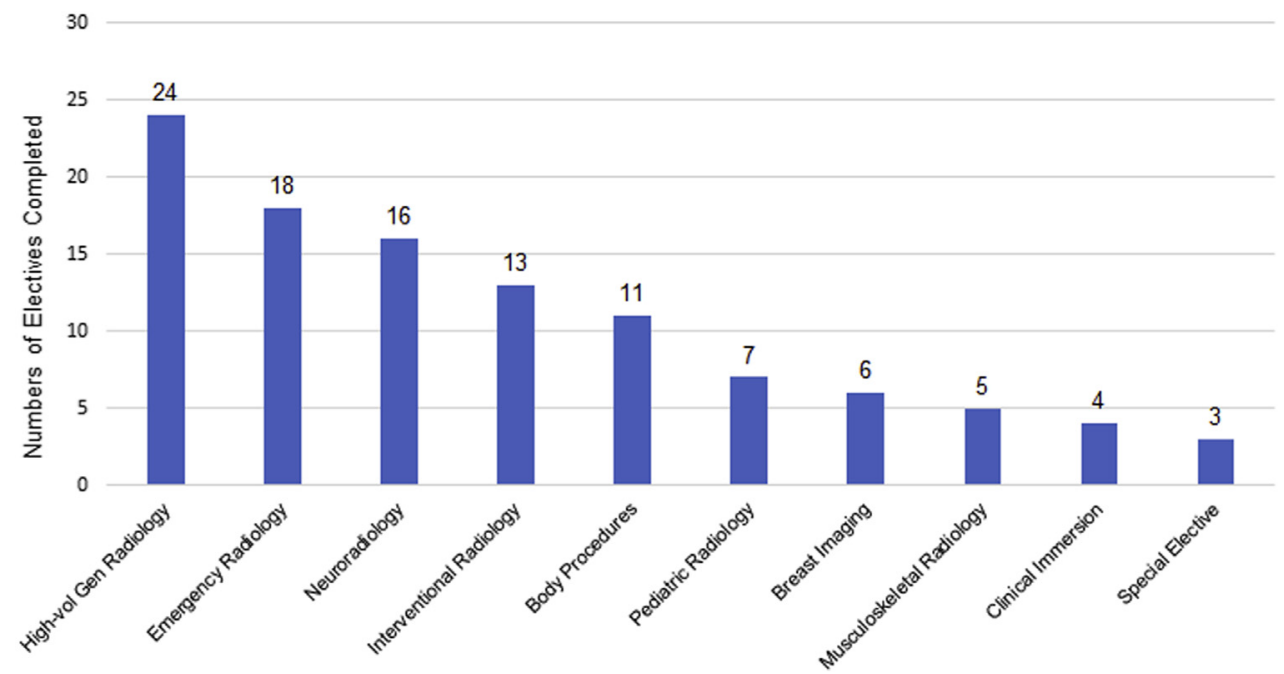

Fig 1. The 10 most popular electives selected by the fourth-year residents in 2015 to 2016 .

an online survey. Once assigned, the resident works closely with the radiology faculty member who routinely provides support to that multidisciplinary conference. The resident is expected to manage the radiology portion of the conference, reviewing the imaging studies with the multidisciplinary group and handling all of the radiology-directed questions. The faculty liaisons also attend each conference to answer any complex questions that might be asked by clinical care providers and to provide ongoing resident feedback. We have found that requiring fourth-year residents to take responsibility for multidisciplinary conferences helps them to better understand complex issues regarding patient management, improves their ability to communicate with clinicians, and reinforces the importance of a multidisciplinary team approach to patient care.

\section{OUTCOMES}

A nine-question web-based survey (SurveyMonkey, Palo Alto, California, USA) was distributed by e-mail to the 15 fourth-year residents who graduated from the Indiana University Radiology Residency in June 2016. Survey questions were designed to elicit how many high-volume, clinical immersion, and special skills electives residents completed during their fourth year, as well as overall resident feedback regarding the value of these experiences. Resident feedback regarding the multidisciplinary conference requirement was also elicited. Of the 15 fourth-year residents participating in the curriculum, $12(80 \%)$ completed the survey.

The top 10 electives completed by the fourth-year class are depicted in Figure 1. The three most popular electives were all "high-volume" rotations: general radiology, emergency radiology, and neuroradiology. The other two core elements of the fourth-year curriculum-clinical immersion electives and special electives - were relatively less popular with the fourth-year residents. Resident feedback regarding the curriculum is depicted in Figure 2. Of note, 17 of the $22(77 \%)$ residents evaluating the high-volume general radiology elective rated it as an excellent experience for transitioning to independent practice. Additionally, 9 of the $12(75 \%)$ residents evaluating the

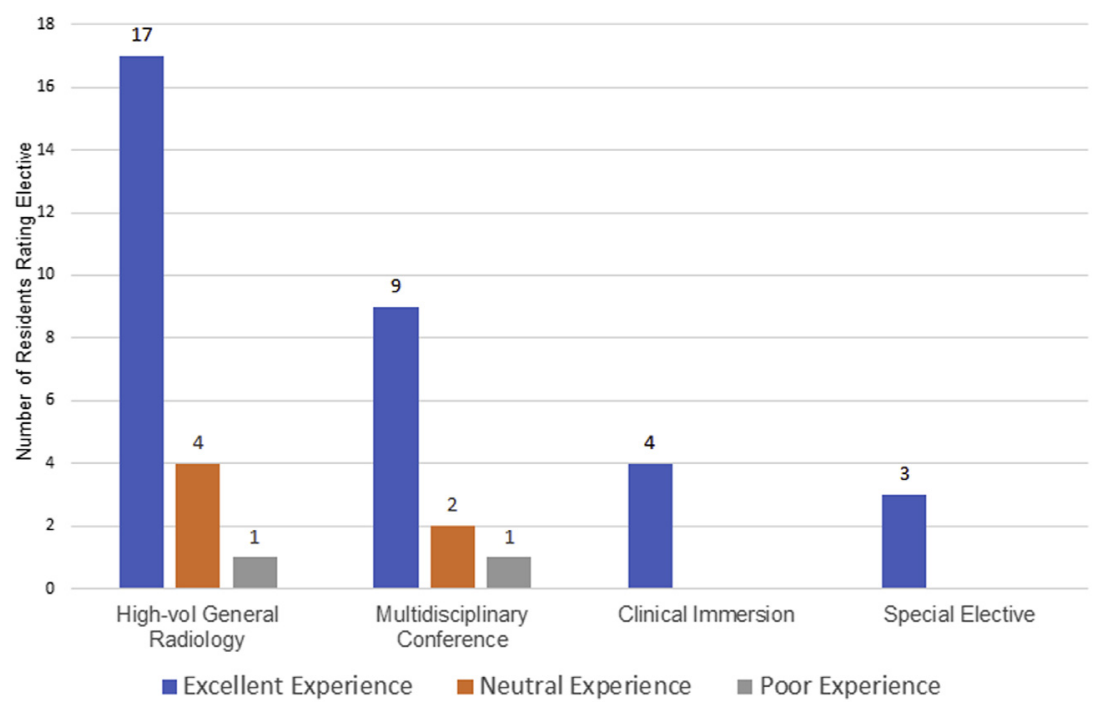

Fig 2. Resident feedback regarding the core elements of the fourth-year curriculum. 
multidisciplinary conference component rated it as an excellent experience for transitioning to independent practice. All residents completing the clinical immersion and special skills electives rated those rotations as excellent transitional experiences.
Other residency programs may consider similar opportunities for their fourth-year residents as a stepwise transition to independent practice.

\section{REFERENCES}

1. Deitte L, Chertoff JD, Mainiero MB, Strife JL, DeStigter KK. Challenges and opportunities in restructuring radiology residencies: the APDR residency restructuring committee report. J Am Coll Radiol 2010;7:507-11.

2. Nicholson BT, Sizemore AW, Gay SB. The new radiology residency fourth year under the new curriculum: a survey of the current residents' thoughts and suggestions about its design and purpose. J Am Coll Radiol 2010;7:294-8.

Darel E. Heitkamp, MD, Jason M. Ford, MD, Colleen M. Madden, MD, Kevin L. Smith, MD, Matthew J. Nartker, MD, John M. Ponting, MD, Scott D. Steenburg, MD, Vasantha D. Aaron, MD, and Aaron P. Kamer, MD, are from the Department of Radiology and Imaging Sciences, Indiana University School of Medicine, Indiana University Hospital, Indianapolis, Indiana.

The authors have no conflicts of interest related to the material discussed in this article.

Darel E. Heitkamp, MD: Department of Radiology and Imaging Sciences, Indiana University School of Medicine, Indiana University Hospital, 550 N University Blvd, Room 0641, Indianapolis, IN 46202; e-mail: deheitka@iupui.edu. 